\title{
Global news highlights
}

\section{WHAT DOES 'DRINK RESPONSIBLY' MEAN?}

All injury prevention advocates will agree that alcohol is a major risk factor in most injuries. An article in Fair Warning describes a study from Johns Hopkins suggesting that slogans such as 'drink responsibly' or 'enjoy in moderation' are meaningless. ${ }^{1}$ Nevertheless, such messages are popular with the alcohol industry because they reduce criticism and may minimise lawsuits. The researcher found that although $87 \%$ of magazine advertisements for these beverages contained a supposed 'responsibility message', no message gave specifics - that is, what is responsible drinking. Worse still, consumers often found language in the advertisements that reinforced marketing themes. The author asserts that health warnings must be specific to change people's behaviour. 'If you want to warn people against something, you need to be clear about what you're warning them against and why.'

\section{INEXPENSIVE HOME IMPROVEMENTS MAY PREVENT FALLS}

A paper in The Lancet suggests that inexpensive home improvements can reduce falls. ${ }^{2}$ The changes proposed include handrails, edging for steps, outside lighting, bathroom grab rails and slip-resistant surfaces. None are particularly novel, but what is unusual is that their effectiveness was established using a modified randomised trial design. Half of 842 homes in New Zealand received modifications and half were assigned to a waiting list comparison group. Over 3 years, the modified homes had 26\% fewer injuries from falls and 39\% fewer falls specific to the home fixes. The average cost per home was 560 New Zealand dollars (about US\$442). An editorial noted that the sample was not large enough to enable the investigators to determine whether the intervention was effective for the elderly and the author wondered if better results might be obtained with customised modifications.

\section{LOWERING STATUS OF CANADA'S CHIEF DOCTOR WORRIES PUBLIC HEALTH COMMUNITY}

Since its inception, the Public Health Agency of Canada (PHAC) has paid little attention to injury prevention. It is now likely to be further weakened by proposed changes to the authority of the chief public health officer. Although the current chief apparently endorses the removal of his status as deputy minister, critics believe this will severely diminish the agency. Authority for running PHAC will shift to a 'president' who is not a health professional. A provincial chief medical officer of health strongly advised a senate committee against approving these changes. When PHAC was created, it was judged essential that its head be a deputy minister and thus able to be the leading national voice for public health. One expert suggested that the new model may be more comfortable for the current political leadership and may reflect its distrust of scientists. 'There has been a pretty systematic effort by this government to silence science and ensure that scientists are not saying things that run against the government's political agenda'.

Editor's comment: Even if the decision is reversed, in my view, PHAC's record on injury prevention remains abysmal.

\section{A REALISTIC PATH TO STOPPING GUN INJURY}

Alpers (University of Sydney) noted that after the Firearms Control Act 2000 was implemented, there was a large decline in gun homicide in South Africa. In 224 other countries surveyed, most have strengthened their firearm legislation. (Only the USA and Canada have moved in the opposite direction.) Alpers asserts that the next step is to get rid of most guns, not just 'illegal guns'. Australia bought back and destroyed a million privately owned guns. Subsequently, the risk of an Australian dying by gunshot fell more than 50\%. In the UK, after the Dunblane massacre, pistols and revolvers were banned and restrictions on long guns tightened. By 2011, there were only 38 gun homicides. In Brazil, gun law reform and buybacks saved 24000 lives in 4 years. Alpers states that to public health practitioners, the gun is to gun violence as the mosquito is to malaria. He believes that death and injury by gunshot can be as amenable to public health intervention as were crashes, drunk driving, smoking and HIV/AIDS.

Editor's comment: Check GunPolicy.org-an excellent sitefor comparisons of armed violence, firearm injury prevention and gun laws across 350 jurisdictions worldwide.

\section{NEED DATA FOR MOST VIOLENT COUNTRY?}

An editorial in the Bulletin of the World Health Organization ${ }^{3}$ surprised me for several reasons. The first was that it revealed that the world's most violent country was Honduras. Among the explanations given are political instability, inequality, corruption, organised crime and the rise of gangs. The second surprise was that the writer believes that to improve matters better data are needed. Not having such data 'hampers a broader analysis and the design of effective programmes and policies .....'

Editor's comment: Undoubtedly, data are incomplete and inaccurate, but I remain to be convinced that better data directly lead to prevention. An equally serious obstacle may be that Honduras has had eight health ministers in the past 8 years!

\section{CHILD HEAD TRAUMA CAUSES}

Data on 43399 children's head injuries were analysed to identify the main causes. The results reported by Quayle et $a l^{4}$ are based on 2004-2006 data from the 25 US emergency departments in the Pediatric Emergency Care Applied Research Network. Most injuries were mild (Glasgow Coma Scores 14-15) and the results are not unexpected. Noteworthy, however, was that a large fraction with brain injuries was not using a safety device. Specifically, $52 \%$ in a car crash were not using a seat belt and $93 \%$ in a bicycle crash were not wearing a helmet.

\section{ASSESSING INTERVENTIONS FOR PRIMARY PREVENTION OF SUICIDE}

A Cochrane review by Harrod et al concluded that suicide is a leading cause of death among postsecondary students worldwide..$^{5}$ This review evaluated the effect of primary suicide prevention interventions targeting this age group. The reviewers included studies that used a randomised controlled trial, controlled before-and-after, controlled interrupted time series or interrupted time series study design. Interventions targeted students without known risk factors, for example, mental illness. Only eight studies met all inclusion criteria and five of these had a high risk of bias.

Editor's comment: As is too often the case, encouraging results were limited to increases in knowledge, not changes in behaviour. So it was not unexpected that the review concluded that there was insufficient evidence to support widespread 
implementation of any programmes or policies for primary suicide prevention.

\section{IMPROVING RAIL SAFETY}

A report in the Montreal Gazette calls attention to the need for more forceful measures to improve rail safety. One year ago an improperly braked train carrying crude oil crashed into a village (Lac Megantic, Quebec). The contents exploded, killing 47 people. The Federal Transport Minister has now announced new regulations to improve safety. These include the number of handbrakes that must be set on stationary trains, the use of wheel chocks or chains and more research on the volatility of crude oil being shipped. The feds also propose to enhance oversight by hiring 10 new staff to enforce the rules and new tankers are replacing existing weak ones. Megantic is the worst rail disaster in modern Canadian history and underscores the dangers of transporting oil by rail.

Editor's comment: That said, I am still not convinced pipelines would be preferable.

\section{US INDUSTRY OPPOSES STRONGER SAFETY REGULATIONS FOR OFF-ROAD VEHICLES}

An item in Fair Warning revealed worrisome opposition to stronger safety measures for all terrain vehicles. Manufacturers have enlisted several US Senators to help block regulations intended to prevent rollover crashes. These senators (eight of 12 of whom have received campaign donations from recreational off highway vehicles manufacturers) urge further discussions with manufacturers about voluntary standards. Consumer product safety officials argue that these standards fail to adequately address key safety issues. Industry believes ROVs are safe and that injuries result from drivers trying risky stunts or failing to heed warnings to wear helmets, use seat belts and avoid alcohol.

\section{DOES DAYLIGHT SAVING TIME REDUCE INJURIES?}

The Royal Society for the Prevention of Accidents urges that England and Scotland be permitted to make their own decisions about moving to a 'single/double summer time' (SDST) system. It does so because it is convinced that 'more daylight on autumn/winter evenings would save lives and reduce injuries on the roads'. Their belief is based on research by the Department for Transport showing that about 80 deaths and 200 serious road injuries would be prevented each year if the UK switched to SDST. One report notes that an extra hour of evening daylight would benefit Scotland more than any other part of the UK because of the limited number of daylight hours it enjoys in the winter.

\section{BLIND CORD STRANGULATIONS STILL A THREAT}

In the US, a window cord fatally strangles an average of one child per month. These cords top a list of the five 'hidden hazards' in the home. The dangers of these cords were identified many years ago and were mentioned in an Injury Prevention editorial in 1996! The key issue now is whether voluntary manufacturing standards and educational programmes provide sufficient protection. I have long felt they do not and it seems I was right. Recently, the Consumer Product Safety Commission (CPSC) voted to start a process that could lead to mandatory safety standards for all new window coverings. It did so in response to a petition filed by seven consumer groups.
Predictably, the industry remained confident that CPSC will ultimately conclude that voluntary standards suffice. They assert that 'The petition's proposal to 'eliminate accessible cords or make cords inaccessible would only result in removing safe products from the market and cost thousands of jobs'. They add that banning corded window coverings could cause consumers to hold onto unsafe products longer.

Editor's comment: In the UK, two recent deaths, one from blind cords, have made strangulation a national priority. In a 5 -year span, 138 children under the age of five years died from 'threats to breathing'.

\section{IMPACT OF DROWNING WORLDWIDE}

WHO released a global report that estimates that 372000 lives are lost each year to drowning. The highest rates involve preschool children and 90\% occur in low-income and middle-income countries. Because many drownings are not reported, the number of deaths is likely to be much higher. The report emphasises that drowning is largely preventable and involves fairly simple and inexpensive solutions. These include barriers, safe swimming places, teaching basic skills and training bystanders in safe rescue and resuscitation. It urges all countries to have a national drowning prevention strategy.

\section{US LATINO WORKERS DIE MORE FREQUENTLY ON THE JOB}

Latino workers increasingly are forced to accept the toughest, dirtiest and most dangerous jobs. Recent data showed that 797 of the 4405 US workers killed on the job in 2013 were Latinos. The actual rates are higher than those for whites, blacks and Asians. The differences may reflect reluctance to protest and weak regulations. The report from Fair Warning notes that 'In most workplace fatality cases, regardless of the race or ethnicity of the employees killed, regulatory penalties are light'.

\section{Ivan Barry Pless}

Correspondence to Dr Ivan Barry Pless, Retired, 434 Lansdowne, Westmount, Quebec, Canada H3Y2V2; barry.pless@mcgill.ca

\section{Competing interests None.}

Provenance and peer review Not commissioned; externally peer reviewed.



To cite Pless IB. Inj Prev 2015;21:68-69.

Inj Prev 2015;21:68-69.

doi:10.1136/injuryprev-2014-041500

\section{REFERENCES}

1 Smith KC, Cukier S, Jernigan DH. Defining strategies for promoting product through 'drink responsibly' messages in magazine ads for beer, spirits and alcopops. Drug Alcohol Depend 2014;142:168-73.

2 Keall MD, Pierse N, Howden-Chapman P, et al. Home modifications to reduce injuries from falls in the Home Injury Prevention Intervention (HIPI) study: a clusterrandomised controlled trial. The Lancet Published Online First: 22 Sep 2014.

3 B-Lajoie M-R, D'Andrea S, Rodriguez C, et al. The need for data in the world's most violent country. Bull World Health Organ 2014;92:698.

4 Quayle KS, Powell EC, Mahajan P, et al. Epidemiology of blunt head trauma in children in U.S. emergency departments. N Engl J Med 2014;371:1945-7.

5 Harrod CS, Goss CW, Stallones L, et al. Interventions for primary prevention of suicide in university and other post-secondary educational settings. Cochrane Database Syst Rev 2014 Oct 29;10:CD009439. 